\title{
Preservation of Fertility in Patients with Cancer
}

\author{
Jacqueline S. Jeruss, M.D., Ph.D. and Teresa K. Woodruff, Ph.D. \\ Department of Surgery (J.S.J.), the Department of Obstetrics and Gynecology (T.K.W.), and the \\ Institute for Women's Health Research (T.K.W.), Northwestern University Feinberg School of \\ Medicine; and the Robert H. Lurie Comprehensive Cancer Center of Northwestern University \\ (J.S.J., T.K.W.) - both in Chicago
}

The unique duality involved in confronting a life-threatening diagnosis while simultaneously considering the deeply human desire to have a child presents a struggle both for patients with cancer and for clinicians. Yet with improved survival rates among young patients with cancer, recent benchto-bedside translation of new techniques to preserve fertility, and increased awareness of choices for the preservation of fertility, options for family planning are now being offered to patients who have received a diagnosis of cancer. Concerns about fertility are similar for men and women; however, their opportunities for intervention differ considerably. This review describes current and emerging options for the preservation of fertility in patients with cancer and provides a conceptual framework for managing concerns about fertility at the time of diagnosis.

The biomedical community faces four main challenges related to the preservation of fertility in people with cancer: the improvement of patient-specific, life-preserving treatments; the identification and reduction of the threat that cancer treatment poses to fertility; the expansion of safe and effective options for fertility treatment; and the creation of symptommanagement plans for patients who lose endocrine function from the gonads as a consequence of cancer treatment. ${ }^{1}$ Current methods of fertility preservation include hormone stimulation in women and sperm banking in men. New methods for women, such as in vitro follicle maturation and techniques for tissue transplantation, are on the horizon. ${ }^{2,3}$ Decisions about the management of cancer can help to limit the side effects of treatment. Examples include reducing the radiation dosage and eliminating alkylating agents, etoposide, or bleomycin from chemotherapeutic regimens in children with low-risk Hodgkin's disease and using paclitaxel more selectively in patients with breast cancer. ${ }^{4,5}$ Such treatment modifications can help to preserve fertility without compromising cancer care. The goal is to provide and develop methods of fertility preservation that permit a range of options for patients that are linked to a multidisciplinary treatment plan until cancer treatments can be specifically targeted to cancer cells.

\section{Fertility Preservation in Clinical Practice Young Women with Breast Cancer}

Although several malignant conditions affect young women, including melanoma, cervical cancer, leukemia, lymphoma, and ovarian cancer, the cancer with the highest incidence in this population is breast cancer. ${ }^{6}$ In 2008 , approximately 182,000 women in the United States were expected to receive a diagnosis of invasive breast cancer. ${ }^{6}$ Of these patients, an estimated 16,000 were younger than 45 years of age. ${ }^{7}$ Many of these young women were

Address reprint requests to Dr. Woodruff at the Northwestern University Feinberg School of Medicine, 303 East Superior St., Suite 4-115, Chicago, IL 60611, or at tkw@ northwestern.edu.

No potential conflict of interest relevant to this article was reported. 
planning to have children or contemplating the possibility. In some but not all patients, options for the preservation of fertility can be explored before the initiation of therapy.

The stage of the disease at presentation and the biologic features of the tumor often determine the treatment strategy in patients with breast cancer. Patients with small tumors and disease that is in the early stage (stage I) and has favorable biologic characteristics (i.e., estrogen receptor-positive, progesterone receptor-positive, and human epidermal growth factor receptor type 2-negative disease) typically undergo primary surgical treatment. In patients who do not receive chemotherapy after surgery, subsequent treatment may include radiation therapy and antiestrogen therapy for at least 5 years. Standard regimens of radiation therapy for breast cancer are not associated with significant ovarian toxicity, although internal scatter radiation can reach the pelvis and ovaries. Therefore, in vitro fertilization and egg harvesting should not be performed during radiation treatment, and pregnancy should be prevented (Fig. 1A). ${ }^{8,9}$ Indirect evidence provides support for the delay of antiestrogen treatment to allow for pregnancy after surgery and radiotherapy have been completed. ${ }^{10,11}$ Thus, patients with early-stage breast cancer who do not receive chemotherapy and whose baseline fertility is within the normal range have a relatively small treatment-related threat to fertility.

Patients with breast cancer who have tumors larger than $1 \mathrm{~cm}$, cancer that is metastatic to the lymph nodes, or hormone receptor-negative disease often undergo chemotherapy. ${ }^{12}$ These patients face a greater threat to fertility. ${ }^{13}$ Chemotherapeutic agents routinely used for the treatment of breast cancer include cyclophosphamide, fluorouracil, doxorubicin, paclitaxel, and docetaxel. ${ }^{14}$ Alkylating agents, including cyclophosphamide, are quite toxic to the ovaries, particularly to the primordial follicles, which represent the ovarian reserve (Fig. 1A). ${ }^{15,16}$ Although the effect of chemotherapeutic regimens on fertility is predicated on the baseline ovarian reserve, treatment effects become particularly pronounced by the time patients reach 40 years of age. ${ }^{17-19}$ Assessment of the ovarian reserve is complex, especially in patients who have been treated for cancer. The most sensitive predictors of ovarian reserve in patients treated with chemotherapy are basal measurements of serum antimüllerian hormone, follicle-stimulating hormone, inhibin B, and estrogen levels. ${ }^{20,21} \mathrm{An}$ ultrasound-guided antral follicle count can also be helpful in assessing the ovarian reserve in patients treated for breast cancer. ${ }^{20}$

Currently, there are subgroups of patients with breast cancer that is being overtreated; this may lead to unnecessary morbidity. Prognostic markers in addition to disease stage are being incorporated into clinical practice to help guide decisions about treatment. Assays such as the Oncotype DX test, which uses 21 genes to predict breast-cancer recurrence, may help patients and clinicians to make decisions regarding the usefulness of chemotherapy. ${ }^{22}$ More refined selection of patients may allow further tailoring of treatments and help to spare fertility by minimizing unnecessary exposure to toxic chemotherapeutic agents. An algorithm for fertility preservation according to treatment indications in women with breast cancer is shown in Figure 2.

At diagnosis, plans for fertility preservation must take into consideration the individual patient's priorities in conjunction with the recommended treatment strategy. Several options are available to women with cancer who wish to preserve their germ line (Fig. 1B and Fig. 3). Patients may elect to delay cancer treatment in order to undergo one cycle of hormone stimulation, followed by cryopreservation of either a mature oocyte or an embryo. ${ }^{2,3,8,23}$ Both techniques require a delay in cancer treatment for up to 1 month; this may not be an option for some patients. Cryopreservation of mature oocytes is considered experimental, although more than 100 live births have been reported with the use of this technique. ${ }^{24,25}$ 
Fertility preservation in patients with hormone receptor-positive disease who would benefit from systemic chemotherapy requires careful consideration. The association between pregnancy after breast cancer and an increased risk of recurrence has not been shown. ${ }^{26,27}$ But since estrogen receptor-positive and progesterone receptor-positive breast cancer is hormonally driven, ovarian stimulation and the exposure to estrogens and progestins may be contraindicated. The selective estrogen-receptor modulator tamoxifen and aromatase inhibitors have been used during the induction of ovulation in patients with breast cancer, but the benefit of this treatment as compared with that of standard regimens of hormone stimulation requires further study. ${ }^{28}$ Furthermore, although gonadotropin-releasing hormone $(\mathrm{GnRH})$ analogues have been tested in women of reproductive age, the ovarian-protective effect of these agents has not been proved in studies in humans. ${ }^{29}$

Gestational surrogacy may also be considered in patients with breast cancer in order to minimize the hormonal exposure of pregnancy. Patients with less prognostically favorable, hormone receptor-negative tumors may be better candidates for fertility measures that require exposure to elevated hormone levels. However, recent data suggest that estrogens may have an indirect mitogenic effect on hormone receptor-negative cancers. ${ }^{30}$

Consequently, hormone stimulation may have unfavorable effects in both patients with hormone receptor-positive disease and those with hormone receptor-negative disease. This information highlights the need for options for the preservation of fertility in addition to methods requiring hormone stimulation.

Fertility-preservation techniques that do not require hormonal exposure are available. Ovarian tissue can be obtained at the time of diagnosis without additional hormonal stimulation, thus only minimally interfering with the patient's treatment plan (Fig. 1B). Depending on the day of the menstrual cycle, oocytes may be aspirated from the ovary, matured in vitro, and then cryopreserved for later use. ${ }^{31}$ In addition, individual follicles or strips of ovarian cortical tissue can be cryopreserved directly for future use in either in vitro follicle maturation or tissue transplantation. Thus far, five live births have been reported in women with cancer who underwent autologous transplantation of cryopreserved ovarian tissue. ${ }^{32-35}$ In patients without cancer, orthotopic ovarian tissue transplantation between monozygotic twins has resulted in two live births. ${ }^{36}$

Transplantation of ovarian tissue is associated with a risk of reintroducing cancer cells from the transplanted tissue and is thus considered a last option for the preservation of fertility in patients with cancer. Patients with hematologic cancers such as leukemia are at increased risk for this adverse event. ${ }^{37,38}$ Although the incidence of occult ovarian cancer among younger women who are carriers of $B R C A 1$ and $B R C A 2$ mutations appears to be low, the potential for the development of cancer in ovarian tissue makes transplantation a poor option in this patient population as well. ${ }^{39}$ Various clinical approaches and laboratory-based techniques are being used to screen ovarian tissue for the presence of metastatic disease before transplantation. These practices include preoperative imaging, histologic analysis with immunohistochemical staining, polymerase-chain-reaction (PCR) amplification, and real-time PCR. ${ }^{40,41}$ More refined screening techniques that are under development provide support for the option of banking ovarian tissue at the time of cancer diagnosis, with subsequent evaluation of the tissue before transplantation. ${ }^{41,42}$

The potential for reexposure to cancer cells will ultimately be minimized if tissue transplantation can be avoided in favor of oocyte maturation through in vitro follicle maturation. In this procedure, immature follicles are recovered from cryopreserved tissue and grown in vitro. The oocyte is then matured in vitro and used for in vitro fertilization. Although it is still in an experimental stage, in vitro follicle maturation may provide an important new option for young patients with cancer who are not candidates for ovarian 
stimulation or who are not prepared to make a decision regarding the creation of an embryo (e.g., because they do not yet have a partner or donor of choice). Thus far, this technique has been successful in animal models, and experiments involving human tissue are progressing. ${ }^{43,44}$ Natural-cycle in vitro fertilization, in which follicles are aspirated without exposure to exogenous hormone stimulation, is also an emerging option. However, the success rate associated with this technique is low, and a delay in treatment may be required, depending on the cycle stage. ${ }^{45,46}$

Finally, in some patients, fertility preservation is not an option because of either treatmentrelated or theoretical concerns. An option for women who become infertile because of cancer treatment is the use of donor oocytes to have a child either through a pregnancy or gestational surrogacy. Thus, the potential availability of donor oocytes should also be part of the panel of options discussed with patients who are facing gonadotoxic treatments for cancer. Before a patient who has had cancer attempts to become pregnant by means of any fertility-preservation option, a clinical evaluation should be undertaken to ensure that the patient is disease-free. Adoption is also a possibility, although a history of cancer may preclude the patient's eligibility for certain adoption programs.

\section{Men with Cancer}

Fertility challenges in men with cancer are less complex than those in women because of the relative ease of sperm banking. However, several factors can negatively affect male fertility, including disruptions of the hypothalamic-pituitary-gonadal axis, damage to the germinal epithelium, and depression related to the diagnosis of cancer. ${ }^{47}$ Recent studies have concluded that the integrity of sperm DNA is compromised before the initiation of treatment in patients with Hodgkin's lymphoma or testicular cancer. ${ }^{48,49}$ Testicular cancer is particularly injurious to fertility, since the growth factors produced by these cancers can be deleterious to spermatogenesis. Furthermore, treatment of testicular cancer often necessitates removal of the affected testis, significantly decreasing the production of sperm. Surgery is also a primary treatment for prostate cancer and can lead to erectile dysfunction. Radiation therapy, which is used to treat several malignant conditions, is toxic to developing sperm, even at low doses (Table 1). ${ }^{50-53}$ Therapy for prostate, rectal, and testicular cancers can require high-dose pelvic irradiation, which may permanently damage testicular function and also contribute to erectile dysfunction. ${ }^{53}$ Treatment of hematologic cancers also often includes radiation therapy that may negatively affect male fertility. Most cytotoxic forms of chemotherapy are not tumor-specific and target rapidly dividing cell types indiscriminately. Consequently, spermatogenesis is extremely vulnerable to the damaging effects of systemic therapies, and oligospermia or azoospermia often results. ${ }^{9,54-56}$ Referral to a urologist can be helpful in assessing reproductive function and the effect of treatment.

The best option for the preservation of male fertility is cryopreservation of sperm before treatment (Fig. 3). Cryopreservation of human sperm has been reported for up to 28 years; this is possible with no apparent loss of capacity for fertilization. ${ }^{57}$ In the small number of patients presenting with azoospermia, a newer technique called onco-tese, which involves a testicular biopsy and isolation of sperm, shows promise. ${ }^{58}$ Damage to sperm DNA for up to 2 years after completion of therapy has been reported in patients undergoing radiation therapy and chemotherapy for testicular cancer and systemic therapy for Hodgkin's lymphoma. ${ }^{49,59}$ These findings underscore the importance of pretreatment counseling regarding contraceptive use and cryopreservation of sperm before the initiation of therapy. ${ }^{60}$ An algorithm of fertility preservation and treatment in men with cancer has been outlined by Brannigan. ${ }^{47,61}$ 


\section{Children with Cancer}

As the survival rate among children with cancer has improved over the past several years, the quality of life after cancer is coming to the forefront in this patient population. Childhood cancers include hematologic malignant conditions, sarcomas, central nervous system lesions, renal cancer, and bone cancer. ${ }^{62}$ In the United States, new cases of cancers were diagnosed in approximately 10,700 children in $2008 .{ }^{63}$ Of these patients, nearly $80 \%$ were expected to survive. ${ }^{63}$ The issue of fertility preservation in children is complicated by the complexity of obtaining informed assent from minors and the possibility that parental decisions may not ultimately reflect the patient's wishes when he or she becomes an adult. ${ }^{64}$

Treatment regimens for childhood cancers are extremely toxic and pose a threat to the fertility of young patients. In addition to endocrine dysfunction associated with infertility, long-term survivors of childhood cancer face various treatment-related health risks, including neurocognitive dysfunction, cardiopulmonary and musculoskeletal compromise, and renal insufficiency. These patients also have an increased risk of secondary malignant conditions ${ }^{65}$ Efforts to tailor standard therapeutic regimens to the specific disease should help mitigate these risks.

The majority of childhood cancers are managed with a combination of chemotherapy and radiation therapy. Treatment with chemotherapy and radiation may also be necessary in children born with inherited syndromes involving bone marrow failure that frequently progress to aplastic anemia, the myelodysplastic syndrome, or leukemia, thereby necessitating bone marrow transplantation. ${ }^{66}$ These treatments can alter the function of the hypothalamic-pituitary-gonadal axis, as well as cause direct damage to the ovaries by affecting folliculogenesis or inducing premature ovarian failure. ${ }^{67,68}$ The testes are particularly vulnerable because germinal epithelium can be severely damaged, permanently affecting spermatogenesis. The direct toxic effects of chemotherapy and radiation exposure on the gonads is generally dose-dependent. ${ }^{69,70}$ Treatment for leukemia, the most common childhood cancer, involves chemotherapy and often bone marrow transplantation. Anthracyclines used to treat this disease affect both DNA and RNA synthesis, induce DNAdamaging oxygen free radicals, and inhibit topoisomerase II. ${ }^{71}$ The long-term adverse effects of this form of chemotherapy on the gonads have not been well quantified.

Options for fertility preservation in the pediatric population largely overlap those that are available for adults (Fig. 3). Children undergoing chemotherapy can receive GnRH agonists, but this treatment has little protective effect. ${ }^{72}$ Cryopreservation of sperm before the initiation of therapy is the best method of preserving fertility in postpubertal boys. If the young patient is unable to provide a semen sample, electroejaculation or surgical sperm extraction can be performed. ${ }^{73}$ There are no established options for the preservation of fertility in prepubertal boys, although investigational techniques such as cryopreservation of spermatogonial stem cells are being pursued. ${ }^{62}$

Adolescent girls have not been considered to be candidates for assisted reproductive technology, largely because of psychosocial issues surrounding a delay in treatment and acquisition of donor sperm. Oophoropexy to move the ovaries away from the direct toxic effects of a radiation target can be performed in girls. ${ }^{74}$ Gonadal tissue can be cryopreserved in the hope that fertility-preserving methods currently under investigation, such as in vitro follicle maturation, will "catch up" with patients over time and provide salient options later in life. Although children with cancer and their families have not typically been offered options for fertility preservation, such options are now available for this patient population. As fertility-sparing therapies and fertility-preserving techniques continue to evolve, survivors of childhood cancer will have a wider range of choices about fertility and will be less likely to have endocrine imbalances. 


\section{Making Fertility Preservation a Reality for Patients}

An important first step in identifying and communicating options for the preservation of fertility in patients with cancer is the creation of a multidisciplinary board that meets on a regular basis to review cases. Recommendations from this board provide the basis for clear communication between clinicians and patients in order to establish appropriate expectations on the part of patients regarding their options and potential outcomes. The board membership should represent the fields of medical, surgical, and radiation oncology, reproductive endocrinology, urology, obstetrics and gynecology, genetics, psychology, bioethics, and health law, as well as basic reproductive medicine, with the members working together to ensure a thorough assessment of the risk of infertility and options for the preservation of fertility in conjunction with the plan for cancer treatment. Information considered by this team would include the patient's reproductive capacity, genetic factors associated with the cancer diagnosis that could affect the assessment (e.g., in patients with $B R C A 1$ and BRCA2 mutations, oophorectomy is often recommended), and timing of treatments that conforms to both the patient's priorities and medical necessity. A psychologist should be available to help negotiate complex decision making involving patients, their partners or parents, and physicians. Research programs can be discussed to provide clinicians with the latest information from global efforts to improve in vitro follicle maturation, oocyte cryopreservation, and tissue transplantation.

Sophisticated database management is also a necessary part of this effort in order to ensure long-term follow-up of patients and their banked tissue. The Oncofertility Consortium, a multidisciplinary fertility-preservation program for patients with cancer, was recently established with support from the Roadmap for Medical Research program of the National Institutes of Health. Through this consortium, a centralized registry was created to correct deficits in data sharing and reporting in order to expedite the evolution of this field while improving patient care.

\section{Conclusions}

The increasing number of young survivors of cancer with favorable outcomes is defining the need for a more comprehensive approach that will improve the quality of life after cancer, including the preservation of fertility. This new paradigm of treatment raises several complex questions. If a risk factor for infertility can be assessed, what does the patient or parent of a young child do with this information? What if an insurance carrier declines to cover fertility treatment, exacerbating economic disparities in patient care and society as a whole? How can the ethical and legal issues surrounding consent and assent be addressed? Ten years ago, many of these issues were irrelevant, given the status of research in the field of follicle biology at that time. Now these questions are being addressed with the use of an interdisciplinary approach to medical progress and patient care. The opportunity to provide accurate information as well as generational hope is invaluable. Clinicians must break through old practice patterns and understand that young patients will no longer be concerned only with preserving their lives in the present but will want to preserve the fullness of their future as well.

\section{Acknowledgments}

Supported by a grant from the National Institutes of Health (UL1 RR024926).

We thank Robert E. Brannigan, M.D., Jeffrey Chang, M.D., William Gradishar, M.D., Laxmi A. Kondapalli, M.D., Thomas O'Halloran, Ph.D., Lonnie D. Shea, Ph.D., and William Small, M.D., for their critical review of an earlier version of the manuscript, and the members of the Oncofertility Consortium. 


\section{References}

1. Woodruff TK. The emergence of a new interdiscipline: oncofertility. Cancer Treat Res 2007;138:311. [PubMed: 18080653]

2. Agarwal SK, Chang RJ. Fertility management for women with cancer. Cancer Treat Res 2007;138:15-27. [PubMed: 18080654]

3. West ER, Shea LD, Woodruff TK. Engineering the follicle microenvironment. Semin Reprod Med 2007;25(4):287-99. [PubMed: 17594609]

4. Donaldson SS, Link MP, Weinstein HJ, et al. Final results of a prospective clinical trial with VAMP and low-dose involved-field radiation for children with low-risk Hodgkin's disease. J Clin Oncol 2007;25:332-7. [PubMed: 17235049]

5. Hayes DF, Thor AD, Dressler LG, et al. HER2 and response to paclitaxel in nodepositive breast cancer. N Engl J Med 2007;357:1496-506. [PubMed: 17928597]

6. Jemal A, Siegel R, Ward E, et al. Cancer statistics, 2008. CA Cancer J Clin 2008;58:71-96. [PubMed: 18287387]

7. Breast cancer facts \& figures 2007-2008. Atlanta: American Cancer Society; 2007.

8. Falcone T, Attaran M, Bedaiwy MA, Goldberg JM. Ovarian function preservation in the cancer patient. Fertil Steril 2004;81:243-57. [PubMed: 14967351]

9. Arnon J, Meirow D, Lewis-Roness H, Ornoy A. Genetic and teratogenic effects of cancer treatments on gametes and embryos. Hum Reprod Update 2001;7:394-403. [PubMed: 11476352]

10. Gradishar WJ, Hellmund R. A rationale for the reinitiation of adjuvant tamoxifen therapy in women receiving fewer than 5 years of therapy. Clin Breast Cancer 2002;2:282-6. [PubMed: 11899359]

11. Goss PE. Letrozole in the extended adjuvant setting: MA.17. Breast Cancer Res Treat 2007;105(Suppl 1):45-53. [PubMed: 17912635]

12. Razzak AR, Lin NU, Winer EP. Heterogeneity of breast cancer and implications of adjuvant chemotherapy. Breast Cancer 2008;15:31-4. [PubMed: 18224391]

13. Lobo RA. Potential options for preservation of fertility in women. N Engl J Med 2005;353:64-73. [PubMed: 16000356]

14. Rastogi P, Anderson SJ, Bear HD, et al. Preoperative chemotherapy: updates of National Surgical Adjuvant Breast and Bowel Project Protocols B-18 and B-27. J Clin Oncol 2008;26:778-85. Erratum, J Clin Oncol 2008;26:2793. [PubMed: 18258986]

15. Gadducci A, Cosio S, Genazzani AR. Ovarian function and childbearing issues in breast cancer survivors. Gynecol Endocrinol 2007;23:625-31. [PubMed: 17926162]

16. Davis VJ. Female gamete preservation. Cancer 2006;107(Suppl):1690-4. [PubMed: 16902945]

17. Backhus LE, Kondapalli LA, Chang RJ, Coutifaris C, Kazer R, Woodruff TK. Oncofertility consortium consensus statement: guidelines for ovarian tissue cryopreservation. Cancer Treat Res 2007;138:235-9. [PubMed: 18080669]

18. Partridge AH, Ruddy KJ. Fertility and adjuvant treatment in young women with breast cancer. Breast 2007;16(Suppl 2):S175-S181. [PubMed: 17804236]

19. Burstein HJ, Winer EP. Primary care for survivors of breast cancer. N Engl J Med 2000;343:108694. [PubMed: 11027744]

20. Lutchman Singh K, Muttukrishna S, Stein RC, et al. Predictors of ovarian reserve in young women with breast cancer. Br J Cancer 2007;96:1808-16. [PubMed: 17533402]

21. van Beek RD, van den Heuvel-Eibrink MM, Laven JS, et al. Anti-Mullerian hormone is a sensitive serum marker for gonadal function in women treated for Hodgkin's lymphoma during childhood. J Clin Endocrinol Metab 2007;92:3869-74. [PubMed: 17726078]

22. Paik S, Shak S, Tang G, et al. A multigene assay to predict recurrence of tamoxifen-treated, nodenegative breast cancer. N Engl J Med 2004;351:2817-26. [PubMed: 15591335]

23. Roberts JE, Oktay K. Fertility preservation: a comprehensive approach to the young woman with cancer. J Natl Cancer Inst Monogr 2005;34:57-9. [PubMed: 15784825]

24. Stachecki JJ, Cohen J. An overview of oocyte cryopreservation. Reprod Biomed Online 2004;9:152-63. [PubMed: 15333244] 
25. Essential elements of informed consent for elective oocyte cryopreservation: a Practice Committee opinion. Fertil Steril 2007;88:1495-6. [PubMed: 17945220]

26. Blakely LJ, Buzdar AU, Lozada JA, et al. Effects of pregnancy after treatment for breast carcinoma on survival and risk of recurrence. Cancer 2004;100:465-9. [PubMed: 14745861]

27. Ives A, Saunders C, Bulsara M, Semmens J. Pregnancy after breast cancer: population based study. BMJ 2007;334:194. [PubMed: 17158581]

28. Oktay K, Buyuk E, Libertella N, Akar M, Rosenwaks Z. Fertility preservation in breast cancer patients: a prospective controlled comparison of ovarian stimulation with tamoxifen and letrozole for embryo cryopreservation. J Clin Oncol 2005;23:4347-53. [PubMed: 15824416]

29. Meistrich M, Shetty G. Hormonal suppression for fertility preservation in males and females. Reproduction 2008;136:691-701. [PubMed: 18515310]

30. Gupta PB, Kuperwasser C. Contributions of estrogen to ER-negative breast tumor growth. J Steroid Biochem Mol Biol 2006;102:71-8. [PubMed: 17049443]

31. Lee D. Ovarian tissue cryopreservation and transplantation: banking reproductive potential for the future. Cancer Treat Res 2007;138:110-29. [PubMed: 18080660]

32. Donnez J, Dolmans MM, Demylle D, et al. Livebirth after orthotopic transplantation of cryopreserved ovarian tissue. Lancet 2004;364:1405-10. Erratum, Lancet 2004;364:2020. [PubMed: 15488215]

33. Meirow D, Levron J, Eldar-Geva T, et al. Pregnancy after transplantation of cryopreserved ovarian tissue in a patient with ovarian failure after chemotherapy. N Engl J Med 2005;353:318-21. [PubMed: 15983020]

34. Demeestere I, Simon P, Buxant F, et al. Ovarian function and spontaneous pregnancy after combined heterotopic and orthotopic cryopreserved ovarian tissue transplantation in a patient previously treated with bone marrow transplantation: case report. Hum Reprod 2006;21:2010-4. [PubMed: 16585122]

35. Andersen CY, Rosendahl M, Byskov AG, et al. Two successful pregnancies following autotransplantation of frozen/thawed ovarian tissue. Hum Reprod 2008;23:2266-72. [PubMed: 18603535]

36. Silber SJ, DeRosa M, Pineda J, et al. A series of monozygotic twins discordant for ovarian failure: ovary transplantation (cortical versus microvascular) and cryopreservation. Hum Reprod 2008;23:1531-7. [PubMed: 18285322]

37. Oktay K, Buyuk E. Ovarian transplantation in humans: indications, techniques and the risk of reseeding cancer. Eur J Obstet Gynecol Reprod Biol 2004;113(Suppl 1):S45-S47. [PubMed: 15041130]

38. Schenker JG, Fatum M. Should ovarian tissue cryopreservation be recommended for cancer patients? J Assist Reprod Genet 2004;21:375-6. [PubMed: 15672948]

39. Colgan TJ, Murphy J, Cole DE, Narod S, Rosen B. Occult carcinoma in prophylactic oophorectomy specimens: prevalence and association with BRCA germline mutation status. Am J Surg Pathol 2001;25:1283-9. [PubMed: 11688463]

40. Elizur SE, Ben-Yehuda D, Hardan I, Dor J, Meirow D. Detection of microscopic metastasis of solid tumors and hematological malignancies in cryopreserved ovaries. Fertil Steril 2004;82(Suppl):S116.

41. Meirow D, Hardan I, Dor J, et al. Searching for evidence of disease and malignant cell contamination in ovarian tissue stored from hematologic cancer patients. Hum Reprod 2008;23:1007-13. [PubMed: 18344563]

42. Schröder CP, Timmer-Bosscha H, Wijchman JG, et al. An in vitro model for purging of tumour cells from ovarian tissue. Hum Reprod 2004;19:1069-75. [PubMed: 15070872]

43. Xu M, Kreeger PK, Shea LD, Woodruff TK. Tissue-engineered follicles produce live, fertile offspring. Tissue Eng 2006;12:2739-46. [PubMed: 17518643]

44. Telfer EE, McLaughlin M, Ding C, Thong KJ. A two-step serum-free culture system supports development of human oocytes from primordial follicles in the presence of activin. Hum Reprod 2008;23:1151-8. [PubMed: 18326514] 
45. Brown JR, Modell E, Obasaju M, King YK. Natural cycle in-vitro fertilization with embryo cryopreservation prior to chemotherapy for carcinoma of the breast. Hum Reprod 1996;11:197-9. [PubMed: 8671185]

46. Hirt R, Davy C, Guibert J, Olivennes F. Pregnancy after in vitro fertilization-intracytoplasmic sperm injection obtained with a modified natural cycle in a BRCA1 mutation carrier. Fertil Steril 2008;90(4):1199.e25-1199.e28. [PubMed: 18155199]

47. Brannigan RE. Fertility preservation in adult male cancer patients. Cancer Treat Res 2007;138:2849. [PubMed: 18080655]

48. O'Flaherty C, Vaisheva F, Hales BF, Chan P, Robaire B. Characterization of sperm chromatin quality in testicular cancer and Hodgkin's lymphoma patients prior to chemotherapy. Hum Reprod 2008;23:1044-52. [PubMed: 18346994]

49. Tempest HG, Ko E, Chan P, Robaire B, Rademaker A, Martin RH. Sperm aneuploidy frequencies analysed before and after chemotherapy in testicular cancer and Hodgkin's lymphoma patients. Hum Reprod 2008;23:251-8. [PubMed: 18083744]

50. Rowley MJ, Leach DR, Warner GA, Heller CG. Effect of graded doses of ionizing radiation on the human testis. Radiat Res 1974;59:665-78. [PubMed: 4428015]

51. Hansen PV, Trykker H, Svennekjaer IL, Hvolby J. Long-term recovery of spermatogenesis after radiotherapy in patients with testicular cancer. Radiother Oncol 1990;18:117-25. [PubMed: 2164240]

52. Gordon W Jr, Siegmund K, Stanisic TH, et al. A study of reproductive function in patients with seminoma treated with radiotherapy and orchidectomy: (SWOG-8711). Int J Radiat Oncol Biol Phys 1997;38:83-94. [PubMed: 9212008]

53. Nakayama K, Milbourne A, Schover LR, Champlin RE, Ueno NT. Gonadal failure after treatment of hematologic malignancies: from recognition to management for health-care providers. Nat Clin Pract Oncol 2008;5:78-89. [PubMed: 18235440]

54. Witt KL, Bishop JB. Mutagenicity of anticancer drugs in mammalian germ cells. Mutat Res 1996;355:209-34. [PubMed: 8781584]

55. Byrne J, Mulvihill JJ, Myers MH, et al. Effects of treatment on fertility in long-term survivors of childhood or adolescent cancer. N Engl J Med 1987;317:1315-21. [PubMed: 3683460]

56. Lampe H, Horwich A, Norman A, Nicholls J, Dearnaley DP. Fertility after chemotherapy for testicular germ cell cancers. J Clin Oncol 1997;15:239-45. [PubMed: 8996148]

57. Feldschuh J, Brassel J, Durso N, Levine A. Successful sperm storage for 28 years. Fertil Steril 2005;84:1017. [PubMed: 16213859]

58. Schrader M, Muller M, Sofikitis N, Straub B, Krause H, Miller K. “Onco-tese”: testicular sperm extraction in azoospermic cancer patients before chemotherapy — new guidelines? Urology 2003;61:421-5. [PubMed: 12597960]

59. Ståhl O, Eberhard J, Jepson K, et al. Sperm DNA integrity in testicular cancer patients. Hum Reprod 2006;21:3199-205. [PubMed: 16931803]

60. Nalesnik JG, Sabanegh ES Jr, Eng TY, Buchholz TA. Fertility in men after treatment for stage 1 and 2A seminoma. Am J Clin Oncol 2004;27:584-8. [PubMed: 15577436]

61. Clouthier DE, Avarbock MR, Maika SD, Hammer RE, Brinster RL. Rat spermatogenesis in mouse testis. Nature 1996;381:418-21. [PubMed: 8632797]

62. Gracia CR, Ginsberg JP. Fertility risk in pediatric and adolescent cancers. Cancer Treat Res 2007;138:57-72. [PubMed: 18080657]

63. Cancer facts \& figures 2008. Atlanta: American Cancer Society; 2008.

64. Informed consent, parental permission, and assent in pediatric practice: Committee on Bioethics, American Academy of Pediatrics. Pediatrics 1995;95:314-7. [PubMed: 7838658]

65. Marina N. Long-term survivors of childhood cancer: the medical consequences of cure. Pediatr Clin North Am 1997;44:1021-42. [PubMed: 9286298]

66. Alter BP. Diagnosis, genetics, and management of inherited bone marrow failure syndromes. Hematology Am Soc Hematol Educ Program 2007;2007:29-39. [PubMed: 18024606]

67. Chemaitilly W, Mertens AC, Mitby P, et al. Acute ovarian failure in the Childhood Cancer Survivor Study. J Clin Endocrinol Metab 2006;91:1723-8. [PubMed: 16492690] 
68. Sklar CA, Mertens AC, Mitby P, et al. Premature menopause in survivors of childhood cancer: a report from the Childhood Cancer Survivor Study. J Natl Cancer Inst 2006;98:890-6. [PubMed: 16818852]

69. Howell SJ, Shalet SM. Testicular function following chemotherapy. Hum Reprod Update 2001;7:363-9. [PubMed: 11476348]

70. Ash P. The influence of radiation on fertility in man. Br J Radiol 1980;53:271-8. [PubMed: 6991051]

71. Minotti G, Menna P, Salvatorelli E, Cairo G, Gianni L. Anthracyclines: molecular advances and pharmacologic developments in antitumor activity and cardiotoxicity. Pharmacol Rev 2004;56:185-229. [PubMed: 15169927]

72. Blumenfeld Z, Avivi I, Eckman A, Epelbaum R, Rowe JM, Dann EJ. Gonadotropin-releasing hormone agonist decreases chemotherapy-induced gonadotoxicity and premature ovarian failure in young female patients with Hodgkin lymphoma. Fertil Steril 2008;89:166-73. [PubMed: 17601603]

73. Schmiegelow ML, Sommer P, Carlsen E, Sonksen JO, Schmiegelow K, Müller JR. Penile vibratory stimulation and electroejaculation before anticancer therapy in two pubertal boys. J Pediatr Hematol Oncol 1998;20:429-30. [PubMed: 9787314]

74. Tulandi T, Al-Shahrani AA. Laparoscopic fertility preservation. Obstet Gynecol Clin North Am 2004;31:611-8. [PubMed: 15450322] 


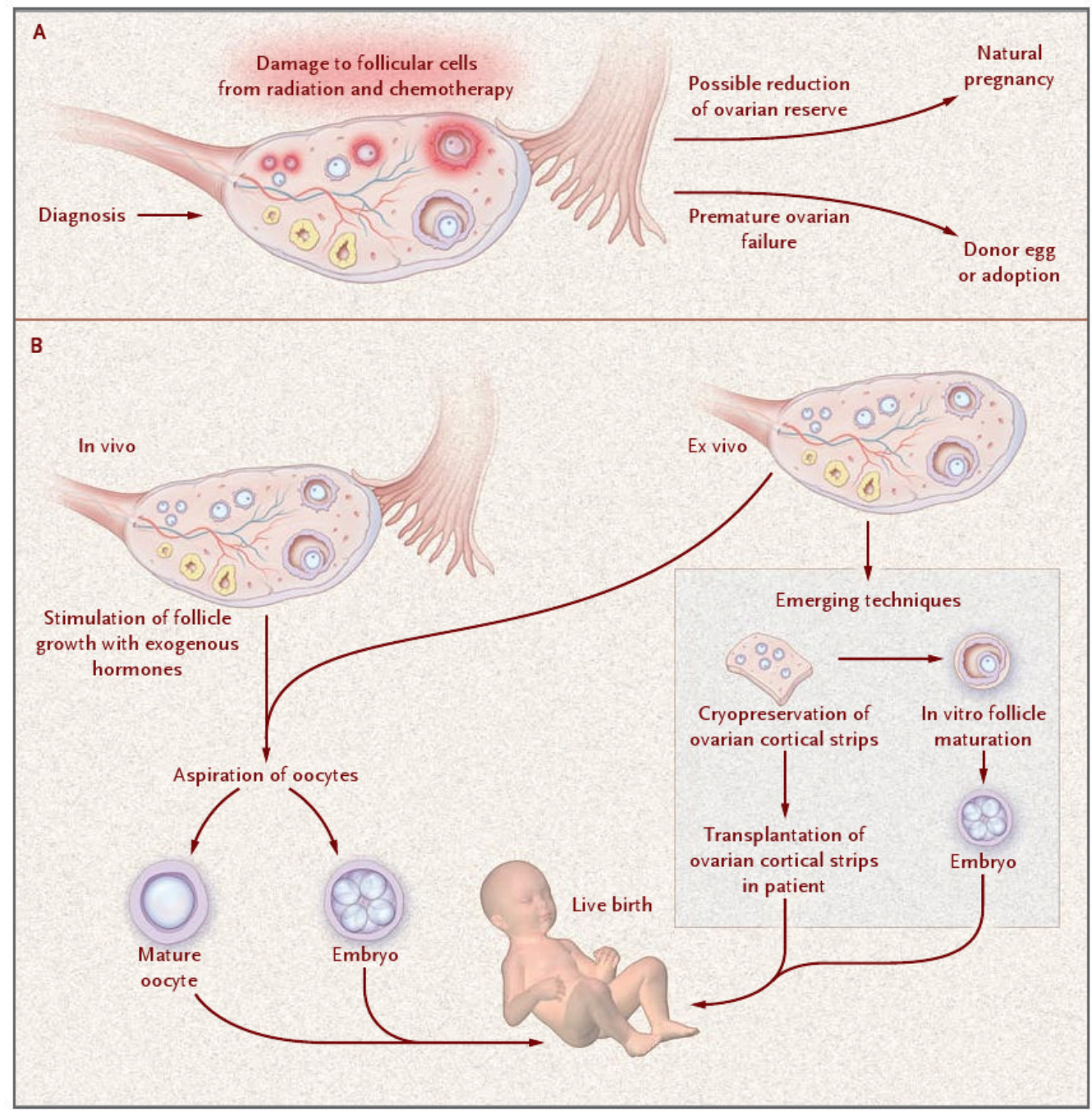

Figure 1. Treatment Effects on Fertility and Options for Preserving Fertility in Women with Cancer

As shown in Panel A, high-dose radiation and most chemotherapeutic agents damage the growing cells in mature and immature follicles and, depending on the type of drug, the dose, and the age of the patient, may result in depletion of many or all follicles. This depletion may result in a short-term loss of reproductive function and an inability to attain a natural pregnancy after treatment. As shown in Panel B, if fertility interventions are warranted, the patient can delay treatment and undergo hormonal induction for 2 to 3 weeks to stimulate follicle development and recover mature oocytes. The oocytes can be frozen or fertilized, depending on the wishes of the patient. If there is insufficient time or if there are contraindications, one ovary can be removed, and ovarian cortical strips can be cryopreserved for use in tissue transplantation or emerging techniques such as in vitro follicle maturation. 


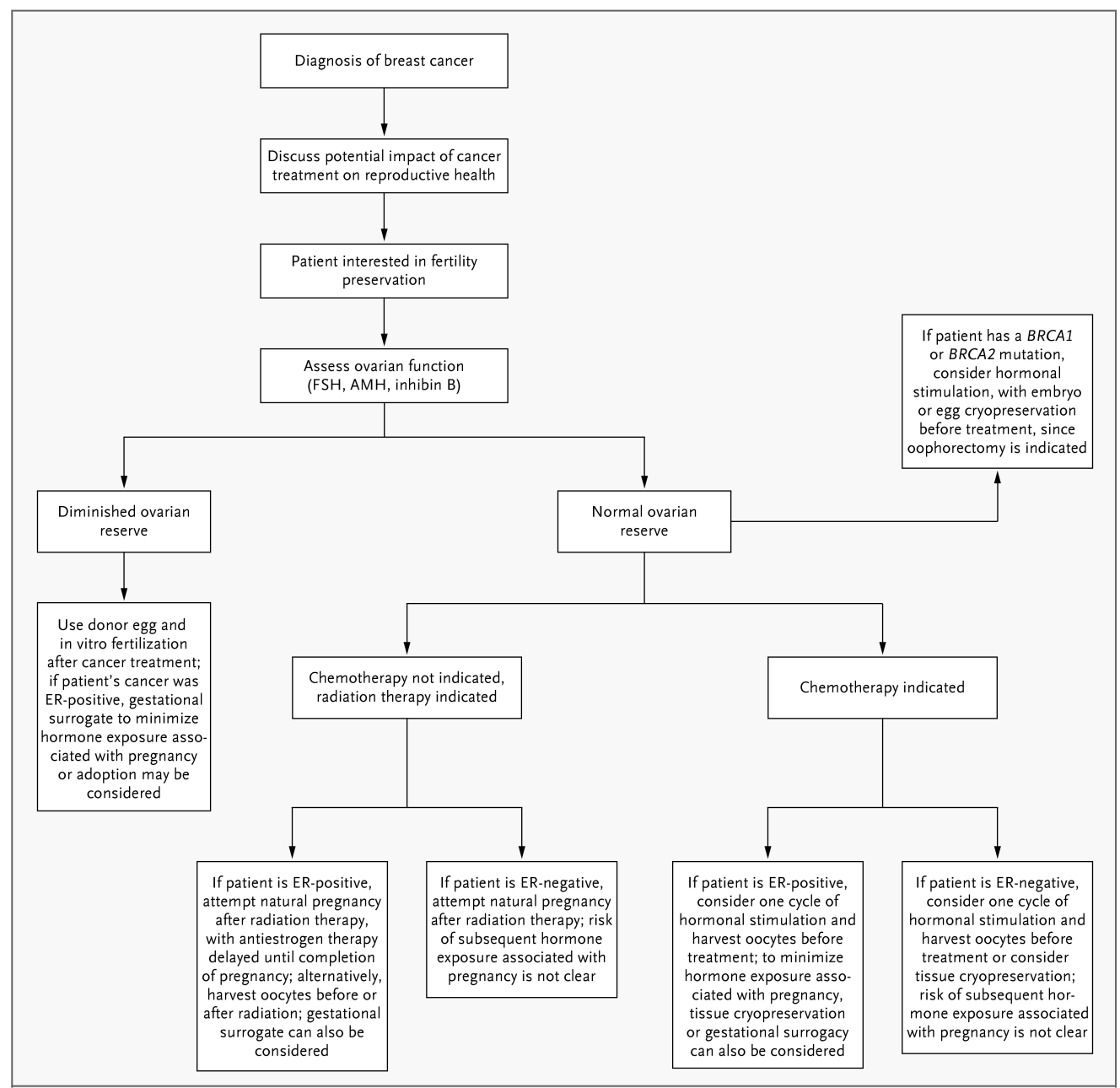

Figure 2. Treatment Guidelines for the Preservation of Fertility in Young Women with Breast Cancer

A discussion about the threat treatment poses to fertility is a critical part of the care of young patients with cancer, in order to allay concerns or offer options for preserving fertility. Some patients may have baseline infertility (i.e., infertility that is independent of the disease), and patients with recurrent disease may have diminished ovarian reserve as a result of previous chemotherapy. The clinician can determine the premenopausal status of the patient by asking about the menstrual history and obtaining a measurement of the follicle-stimulating hormone (FSH) level; an elevated level on an early day in the menstrual cycle indicates diminished ovarian reserve. Strategies for preserving fertility are then established, depending on treatment decisions and the time available for intervention. A multidisciplinary team that provides advice on these cases can help ensure that the complex decisions made by the clinician and the patient are integrated and that risk-benefit discussions about all decisions are clearly delineated. AMH denotes antimüllerian hormone, and ER estrogen receptor. 


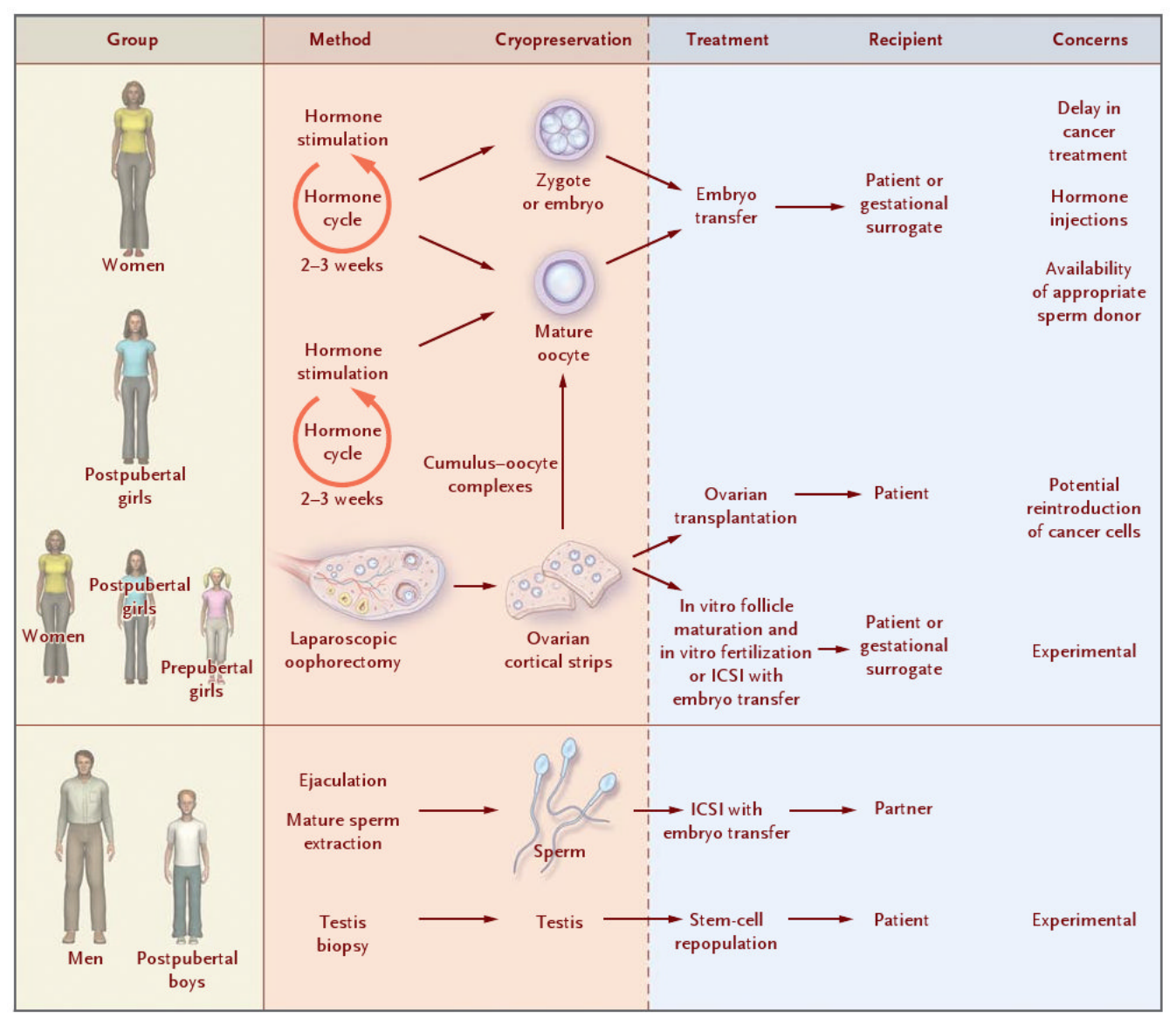

Figure 3. Options for Fertility Preservation in Patients with Cancer

Fertility-preserving options for young women with cancer include hormonal stimulation with cryopreservation of oocytes or embryos and laparoscopic oophorectomy with tissue storage and later use in transplantation or in vitro follicle maturation. At the time of tissue harvest, mature follicles may exist and cumulus-oocyte complexes may be harvested and matured in vitro to provide another source of mature eggs for storage. Depending on the patient's uterine status, a gestational surrogate may be required. Tissue cryopreservation is the only option for girls who are not candidates for hormone stimulation. Cryopreservation of ejaculatory or tissue-extracted sperm is an option in men and postpubertal boys with cancer. ICSI denotes intracytoplasmic sperm injection. 


\section{Table 1}

Recovery of Spermatogenesis after Graded Doses of Ionizing Radiation to the Human Testes.*

\begin{tabular}{|lc|}
\hline Radiation Dose & Time to Recovery \\
\hline$<1 \mathrm{~Gy}$ & $9-18 \mathrm{mo}$ \\
\hline $2-3 \mathrm{~Gy}$ & $30 \mathrm{mo}$ \\
\hline$\geq 4 \mathrm{~Gy}$ & $>5 \mathrm{yr}$ \\
\hline
\end{tabular}

* Data are from Rowley et al. ${ }^{50}$ Limited data are available on other dose ranges (e.g., 1 to 2 Gy and 3 to 4 Gy). Recovery is defined as a return to the sperm concentration before irradiation. 